The University of Akron

\title{
IdeaExchange@UAkron
}

Proceedings from the Document Academy

University of Akron Press Managed

December 2016

\section{Gatekeeping in Crisis Communication: An Exploration of Leadership in the Press Conference}

Carrie A. Boettcher

Emporia State University, cboettch@emporia.edu

Please take a moment to share how this work helps you through this survey. Your feedback will be important as we plan further development of our repository.

Follow this and additional works at: https://ideaexchange.uakron.edu/docam

Part of the Library and Information Science Commons, and the Mass Communication Commons

\section{Recommended Citation}

Boettcher, Carrie A. (2016) "Gatekeeping in Crisis Communication: An Exploration of Leadership in the Press Conference," Proceedings from the Document Academy: Vol. 3 : Iss. 2 , Article 3.

DOI: https://doi.org/10.35492/docam/3/2/3

Available at: https://ideaexchange.uakron.edu/docam/vol3/iss2/3

This Conference Proceeding is brought to you for free and open access by University of Akron Press Managed at IdeaExchange@UAkron, the institutional repository of The University of Akron in Akron, Ohio, USA. It has been accepted for inclusion in Proceedings from the Document Academy by an authorized administrator of

IdeaExchange@UAkron.For more information, please contact mjon@uakron.edu, uapress@uakron.edu. 
Growing up in tornado alley in the Midwest, I recall many spring and summer afternoons and evenings gathered around the television or listening to the local radio station to identify when severe weather would arrive. A particularly dangerous thunderstorm was on the way if the local meteorologist cut into regular programming to track the movement of the storm and warn citizens of the need to take action. For many in tornado alley during severe weather season, these were our sources of authority in which we placed our trust to detail our activities for the day and when we needed to seek shelter from the storm. It is from this everyday context that Patrick Wilson's call to "a reorientation toward the functional" and "to the point of the user" was applied.

Wilson's call is explored through crisis communication efforts of two large-scale disasters experienced in the United States viewed through the lens of gatekeeping theory. Of particular interest are the initial press conferences of the Mayor of New York City, Rudolph Giuliani, in response to the World Trade Center attacks on September 11, 2001 (referred to as 9/11) and the early incident communications of the Mayor of New Orleans, Ray Nagin, Jr. during the days leading up to and just following landfall of Hurricane Katrina in 2005 (referred to as Hurricane Katrina). This process of thinking through ideas is clearly exploratory rather than a critical review of the literature and touches specific instances within the disasters rather than the full scope of each disaster. The phenomenological and social aspects of the press conference as document provide the foundation of this thought process, yet a full discussion of these concepts is beyond the scope of this exploration. Each disaster is viewed from broad descriptions or generalizations of the events. Also working from the exploratory perspective, gatekeeping in crisis communication is viewed from Kurt Lewin's concepts of channels and force. Within this discussion, the early press conferences of a disaster event presumably provide information to the public, potentially filtered information, and there are forces within the disaster scenario that influence the information shared. I acknowledge these broad assumptions and limitations in scope potentially influence the direction, flow, and pursuit of this topic as a potential research study. As one of the most beneficial elements of this process, the discussions and reflections offered during DOCAM'16 provided valuable insight to further refine this exploration into a viable research topic.

"Scholars studying $21^{\text {st }}$-century mass media must return to Lewin's original application of the theory- studying social change" (Shoemaker \& Vos, 2009, p. 132).

It was a personal experience with emergency communications during the severe weather season of 2013 in the midwest of the United States that prompted this 
exploration into leadership and gatekeeping. Emergency preparedness and response messaging have been studied from the perspective of the individual, groups, communities, cultures, government, technology, systems, and information. Although this is not an exhaustive list, or a comprehensive view of disaster research, the knowledge base upon which current crisis communications develops is not a new concept. Yet each year lives are lost, and natural and manmade disasters harm the environment.

Acknowledging that life in the 21st century is dynamic and continuously evolving, Merton's (1976) definition of social problems, "a discrepancy between cultural standards, norms, or values and the actual conditions of social life, a discrepancy between what should be and what is" (p. 7), provides the connection between disasters, gatekeeping, and leadership. Community leaders, by nature of their position in the community, carry a position of authority and power that is reflected in crisis communications as a gatekeeping function or position. As such, crisis communication by community leaders is a key element of social change preparing for and responding to disasters.

A reorientation toward the functional...

"different scales of action require different types of information and different means of communication to create a 'common knowledge base' to support collective action against threats at each jurisdiction, and successively for the response system" (Comfort, Oh, Ertan, \& Scheinert, 2010, p. 35).

The responsibility of emergency managers, emergency communication professionals, public information officers, and community leaders is that of the larger community or jurisdiction. Acknolwedging the challenge to reach each individual, emergency communication is intended for large groups of people such as communities, counties, school populations, employees of large corporations, and venues with large crowds such as entertainment facilities. Emergency information is created based on the nature of the emergency event, recorded through a medium such as television, radio, social media, and printed flyers so the information will eventually be disseminated, diffused, and utilized by individuals to take action before and during an emergency.

Those attempting to craft emergency messages negotiate multiple forces simultaneously as they attempt to provide accurate, timely, and needed communication during emergencies. Although some forces are rather technical and require consultation with subject matter experts or legal counsel before 
dissemination of the message, multiple logistical forces also influence the crisis communication process. Power may be limited or cell phone towers may have been damaged that disrupt the flow of communication. Appropriately trained personnnel may have been impacted by the disaster leaving a gap in skills and expertise to craft and communicate emergency messages. In the early stages of a disaster, information may be insufficient, fragmented, or conflicting, further adding to the challenge of accurate, timely, and needed information to improve life safety for all involved.

"an event, concentrated in time and space, in which a society or a relatively selfsufficient subdivision of a society, undergoes severe danger and incurs such losses to its members and physical appurtenances that the social structure is disrupted and the fulfillment of all or some of the essential functions of the society is prevented" (Fritz, 1961, p. 655).

The terms emergency, crisis, disaster, risk, and hazard are used interchangeably throughout the literature to imply various impacts of emergency situations. Scholars describe emergency situations in the literature based on their theoretical and philosophical background. Although Lindell, Prater, and Perry (2007) provide a general definition of emergency as a "situation [that] requires prompt and effective action" (p. 3), it is the urgency and change in the social structure within Fritz's (1961) definition of disaster that more closely describes the events explored within this paper and DOCAM'16.

Investigations into understanding emergency preparedness and response efforts are founded on the need to improve life safety and property preservation, two fundamental elements of emergency management and emergency response. Scholars from a multitude of disciplines have investigated these topics from equally diverse worldviews and points of focus. The current exploration continues to develop this understanding through an exploration of disaster from an information perspective.

Embedded within crises and disasters are information challenges such as information overload, an increase of information produced about the crisis, formal and informal channels of communication, evolving information needs, and information uncertainty and conflicting information (Hagar, 2012). The dynamics of evolving crisis situations highlight the reality that "information needs are temporal and may shift and evolve over time and place as people interact with, interpret, and make sense of information" (O'Brien \& Greyson, 2015). Characteristics of disaster include disruption of the social structure and interruption of daily life. As experienced during the 9/11 and Hurricane Katrina 
disasters, not only has daily life and the environment changed, but such changes necessitated action to respond to and survive the event.

Emergency planning and response, including crisis communication, mitigate the effect of and response to the impact of emergency and disaster situations. Emergency communication, also known as risk or crisis communication, assumes the dissemination of hazard-specific information will assist with decision-making during an emergency or crisis (Mileti, 1999). Dissemination, diffusion, and utilization of information are critical elements of emergency communication in an emergency or disaster because a lack of information can lead to confusion, anxiety, and rumors, especially if the public believes information has been withheld (Waugh \& Tierney, 2007). Although crisis communication is a constantly evolving landscape utilizing low-tech and high-tech options, this exploration included commonly utilized communication tools, the onscreen television interview as well as an on-air radio interview. The intent of this exploration was to compare onscreen press conferences from two large-scale disasters, however, given the nature of the situations this was not accomplished. The 9/11 and Hurricane Katrina disasters both resulted in power loss in the impacted areas. However, the loss of power due to not only the hurricane but also the breach of levees in New Orleans proved detrimental to communications in the area. As a result, rather than reviewing two onscreen interviews, the crisis communications reviewed included one onscreen television interview and one onair interview.

The orientation of a call to the functional and the information user provided the framework from which to select crisis communications for review in this study. The initial communications by Mayors Giuliani and Nagin focused on life safety of the public. Therefore, only crisis communications that could be found online by the public, without special clearance or requests to communication organizations, were selected for review. As a result, YouTube served as the database for this exploration. Acknowledging the diverse backgrounds of DOCAM participants, two videos oriented viewers to the disasters of focus for this study. The disasters were explored chronologically with "setting the stage" videos followed by two crisis communications provided by community leaders as a result of 9/11 and Hurricane Katrina. 
September 11, 2001

Orientation

https://youtu.be/8tgQ75GxAZk (approximately 1:15 viewed)

Crisis Communications

https://youtu.be/BukRhFEZtC8 (approximately 0:56 viewed)

https://youtu.be/xhBYWDy4m9M (approximately 1:15 viewed)

Hurricane Katrina, 2005

Orientation

https://youtu.be/LwAuYk0_37g (approximately 1:45 viewed)

Crisis Communications

https://youtu.be/9upJ1vRCgoo (approximately 1:30 viewed)

https://youtu.be/W53k7uHh_t4 (approximately 2:10 viewed)

"adaptive leadership is the behavior of leaders and the actions they take to encourage others to address and resolve changes that are central in their lives" (Northouse, 2016, p. 258).

It was the result of viewing $9 / 11$ and Hurricane Katrina through the lens of leadership and gatekeeping that the similarities and differences of the incidents became apparent. Both situations involved large-scale disasters crossing multiple jurisdictional boundaries that changed not only how emergency planning and response occurs in the United States, but also the lives of Americans whether or not they lived in the affected areas. Also, both incidents included multiple emergencies within the disaster such as loss of power, travel and mobility disruption, interruptions to communication, multiple populations affected, overwhelmed local and state resources, potential impacts were difficult to comprehend prior to the incident, both cities were well-known travel destinations nationally and internationally, and the incidents carried economic impacts outside the disaster area. Hazard analysis identified both locations as vulnerable to disasters before the incidents contributing to controversy, confusion, anxiety, and rumors that flowed freely following the $9 / 11$ and Hurricane Katrina disasters. In the political realm, President George W. Bush served as the $43^{\text {rd }}$ President of United States during both disasters. 
With such significant similarities, it was the realization of the differences between the incidents that a comparison of leadership within the community through crisis communication efforts that proved to be challenging. The sudden occurrence of the 9/11 disaster included terrorist attacks on the economic district of New York with no pre-event warnings to the public. A terrorist attack provided an individual or group to direct grief and anger. Evacuation occurred after the event was in progress and did not include extensive areas. In contrast, planning for Hurricane Katrina began in advance of landfall of the hurricane and crisis communications included conflicting messages that the National Weather Service forecast a dangerous storm unlike they had seen before 2005, yet economic needs influenced evacuation planning rather than life safety. With the exception of individuals in the World Trade Center Towers, the areas within New York City that were impacted by the incident included a substantial number of affluent individuals with the capacity to evacuate the area. New Orleans evacuation procedures prompted a situation in which the mandatory evacuation issued the day before the storm reached landfall primarily targeted vulnerable populations within the city. Prior to the mandatory evacuation, Mayor Nagin announced $80 \%$ of the citizens of New Orleans had evacuated the area (Frontline, 2016, para. 11). Therefore, the affluent citizens capable of evacuation, presumably with a means to evacuate, and a safe place to shelter away from the storm had already left the city. Those without the capability to evacuate remained.

The disaster in New York City provided an opportunity to view the mayor through the lens of gatekeeper- did the mayor answer questions based on information known at the time, or avoid questions to detract from his decision to house the city's emergency operations center in the World Trade Center complex despite recommendations to the contrary? It was through the investigation of the disaster in New Orleans that indicated the two incidents were not as similar as originally thought. The evacuation process of New Orleans prompted more questions about the mayor's control and power influence in the community than leadership within the community, as exhibited in crisis communications. Although the mayor was in the position to provide support and encourage citizens of New Orleans to adapt to the changing environment and situation before the storm, the mayor focused communication efforts toward businesses until the mandatory evacuation. The communication provided following landfall of the hurricane and breach of the levee system in New Orleans focused on government support, or lack of support, of the response. A relationship between gatekeeping and leadership is not clear without further investigation to understand the role of communication disruption in the gatekeeping process. Due to the nature of the flooding in the area, the press conference may not have been the most funtional method of communication at the time. Perhaps an investigation into the evacuation plans of New Orleans pre- and post- Hurricane Katrina would prove 
more substantial to Wilson's call to action than an investigation of the crisis communication efforts of government leaders at the time.

To the point of the user...

"For costly ignorance may be irreparable; even presenting the crucial information in the most palatable possible form may lead to no change of behavior" (Wilson, 1977, p. 66).

Emergency communication occurs before an emergency event occurs, during the emergency, and after the emergency event. Pre-event communication focuses on preparedness actions to plan for a potential or impending emergency event. Emergency messages provided during an emergency event focus on actions to take now to respond to the emergency. Post-event messaging focuses on needs or actions to take based on the particular emergency. An underlying theme in the emergency communication described is to take action.

The initial moments during and immediately following an emergency have a profound impact on the perceptions of individuals experiencing the event, the response efforts, and recovery from the emergency event. The response provided during the initial communication efforts of leadership have a lasting influence on first responders and the community, often setting the tone for future communication and response activities. The press conference is one of many communication efforts within crisis communications. Throughout my lifetime the press conference signaled a significant situation that required my attention. Although crisis communication continues to evolve, the press conference is likely to remain an appropriate tool to communicate accurate, timely, and needed information to large numbers of people throughout emergency events.

The public's awareness of hazards, and businesses' understanding that disasters can disrupt or halt their operations, is vital to understanding the critical importance of emergency communication to reduce the loss of life and property in an emergency (Lindell, Perry, \& Prater, 2007). Through open communication and collaboration, asynchronous emergency information created by emergency managers, emergency communication professionals, public information officers, and community leaders is recorded and disseminated to the public as change agents to influence behavior to prepare for and respond to emergencies. 
"In science as in life, it is well known that a chain of events can have a point of crisis that could magnify small changes. But chaos meant that such points were everywhere. They were pervasive. In systems like the weather, sensitive dependence on initial conditions was an inescapable consequence of the way small scales intertwined with large" (Gleick, 2008, p. 23).

Participants of DOCAM'16 provided insightful and valuable feedback to this exploration of crisis communication. After viewing the orientation videos and crisis communications from 9/11 and Hurricane Katrina, participants were asked what word or comment described their thoughts as a result of watching the video or communication. Comments captured below include approximate representations of feedback provided.

Feedback after the 9/11 crisis communications included: sensemaking, authority, chaos, tension of knowing-formation over time, management of emotion direction, disruption, the first post-incident video appeared calculated- news emphasized, and I want the truth, not your filter.

Feedback after the Hurricane Katrina crisis communications included: moves from facts to narratives to build stories, constructing facts, transcription building, crisis to construction of national politics- especially international contextual development.

In many ways, it was the discussion after the presentation that proved more beneficial than the preparation for the presentation. My questions currently outnumber answers as a result of this exploration. However, I have found that Wilson's call to action is an appropriate framework from which to investigate crisis communication, emergency planning as a preparedness tool as well as an identification of cultural vulnerability, situational awareness in emergencies, response to disasters at the individual, group, and community level, or leadership in emergency situations, to name a few. It seems most appropriate for Wilson to offer a conclusion for this exploration.

"Scholarly and scientific inquiry is a public enterprise, with a public goal, that of adding to or improving the public stock of knowledge. Scholars and scientists are by no means the only ones who make contributions to the stock" (Wilson, 1977, p.

$3)$. 


\section{References}

Authentic History Center. (2011). 9/11 news coverage: 9:50 AM: Mayor Giuliani street interview. Retrieved from https://youtu.be/BukRhFEZtC8

Authentic History Center. (2011). 9/11 news coverage: 2:38 PM: Giuliani-Pataki press conference. Retrieved from https://youtu.be/xhBYWDy4m9M

Comfort, L. K., Oh, N., Ertan, G., \& Scheinert, S. (2010). Designing adaptive systems for disaster mitigation and response: The role of structure. In Comfort, L. K., Boin, A., \& Demchak, C. C. (Eds.). Designing resilience: Preparing for extreme events (pp. 33-61). Pittsburgh, PA: University of Pittsburgh Press.

Destitutebroadcast. (2014). 911 jumpers: Plane crashes World Trade Center Towers September 11. Retrieved from https://youtu.be/8tgQ75GxAZk

Fett, K. (2016). Hurricane Katrina: NBC Today (08/30/05). Retrieved from https://youtu.be/LwAuYk0_37g

Fritz, C. (1961). Disaster. In R. K. Merton \& R. A. Nisbet (Eds.), Contemporary social problems, (pp. 651-694). New York: Harcourt Press.

Frontline. (2016). The storm: 14 days a timeline. Retrieved from http://www.pbs.org/wgbh/pages/frontline/storm/etc/cron.html

Gleick, J. (2008). Chaos: Making a new science (20 th annv. ed.) New York, NY: Penguin.

Hagar, C. (Ed.). (2012). Crisis information management: Communication and technologies. Oxford, UK: Chandos Publishing.

Lindell, M. K., Prater, C., \& Perry, R. W. (2007). Introduction to emergency management. Hoboken, NJ: Wiley.

Merton, R. K. (1976). The sociology of social problems. In R. K. Merton \& R. A. Nisbet (Eds.), Contemporary social problems ( ${ }^{\text {th }}$ ed., pp. 3-43). New York: Harcourt, Brace Jovanovich.

Mileti, D. S. (1999). Disasters by design: A reassessment of natural hazards in the United States. Washington, DC: Joseph Henry Press.

Northhouse, P. G. (2016). Leadership: Theory and practice ( $7^{\text {th }}$ ed.). Thousand Oaks, CA: Sage. 
O'Brien, H. \& Greyson, D. (2015). Information needs: Understanding and responding to today's information user. In S. Hirsh (Ed.), Information services today (pp. 119-129). New York, NY: Rowman \& Littlefield.

RPTN. (2007). Hurricane Katrina: Part 1: The true story: Ray Nagin. Retrieved from https://youtu.be/W53k7uHh t4

Shoemaker, P. J. \& Vos, T. P. (2009). Gatekeeping theory. New York, NY: Routledge.

Storm Coverage. (2014). Hurricane Katrina coverage: Evacuation ordered (08/28/2005): CNN. Retrieved from https://youtu.be/9upJ1vRCgoo

Waugh, W. L., \& Tierney, K. J. (2007). Emergency management: Principles and practice for local government. Washington, DC: ICMA Press.

Wilson, P. (1977). Public knowledge and private ignorance. Westport, CT: Greenwood Press. 